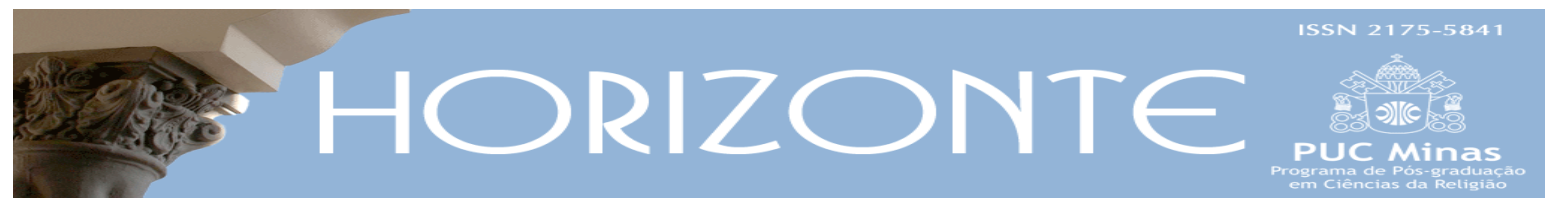

Dossiê: Espiritualidades, Filosofias e Religiões do Oriente - Artigo Original (c) (i) DOI - 10.5752/P.2175-5841.2016v14n43p827

\title{
Budismo social e engajado: \\ a experiência do CEBB e de Lama Padma Samten
}

\author{
Social and Engaged Buddhism: \\ The CEBB Experience and Lama Padma Samten
}

Deyve Redyson*

\begin{abstract}
Resumo
Este trabalho tem como principal objetivo fazer uma recuperação histórica do surgimento do CEBB (Centro de Estudos Budistas Bodisatva) e suas experiências como veículo de divulgação do budismo tibetano no Brasil, bem como da própria trajetória do Lama Padma Samten, seu fundador, e atual liderança religiosa desta tradição. Pretende-se demonstrar que a experiência do CEBB configura-se numa forma de budismo social e engajado, onde perspectivas voltadas para a educação, a assistência social e a preservação e respeito dos direitos humanos são elementos que o aproximam da realidade brasileira. A experiência vivenciada do CEBB também se liga ao trabalho em comunidades de grande risco social, mas sempre conectada com as identidades brasileiras de budismo que se espelham na ação altruísta, baseadas na generosidade e contemplação. Vinculados ao CEBB também está, em grande parte, a história e os desenvolvimentos do budismo no Brasil, que apontam estatísticas de crescimento e expansão, como resultado do trabalho social engajado e da responsabilidade universal com os seres humanos.
\end{abstract}

Palavras-Chave: Lama Padma Samten; Engajamento; Budismo Social; Budismo no Brasil.

\begin{abstract}
This work aims to make a historical recovery of the emergence of CEBB (Centro de Estudos Budistas Bodisatva) and his experiences as a vehicle for dissemination of Tibetan Buddhism in Brazil, as well as the very trajectory of Lama Padma Samten, its founder, and current religious leadership of this tradition. We intend to demonstrate that the CEBB experience set in a form of social and engaged Buddhism where prospects facing on education, social welfare and the preservation and respect for human rights are elements that approach the Brazilian reality. The lived experience of CEBB also binds to work at great social risk communities, but always connected with Brazilian identities of Buddhism that mirror the altruistic action, based on generosity and contemplation. Linked to CEBB it is also, in large part, the history and development of Buddhism in Brazil that link growth statistics and expansion as a result of social work engaged and universal responsibility with human beings.
\end{abstract}

Key-Words: Lama Padma Samten; Engagement; Social Buddhism; Buddhism in Brazil.

Artigo recebido em 01 de março de 2016 e aprovado em 30 de setembro de 2016.

* Doutor em Filosofia e Professor do Departamento de Ciências das Religiões e do Programa de Pós-graduação em Ciências das Religiões da Universidade Federal da Paraíba - UFPB. País de Origem: Brasil. E-mail: dredyson@gmail.com.

Horizonte, Belo Horizonte, v. 14, n. 43, p. 827-858, jul./set. 2016 - ISSN 2175-5841 


\section{Introdução}

Nos dias de hoje falar de um engajamento social no budismo é rememorar os ensinamentos do Buddha Shakyamuni, registrados nos cânones ${ }^{1}$. O tema do engajamento social reflete uma ação prática perante a realidade natural que assistimos todos os dias, às vezes inertes a ela, outras vezes assumindo a coparticipação nesta realidade. O engajamento social budista é um entendimento dos ensinamentos do Buddha para as realidades e vivências de hoje, isto é, podemos entender por budismo social uma categoria de budismo que se envolve com a ação, imediata ou não, que propõe mudanças estruturais em determinadas peculiaridades da vida humana. Dessa forma, ao falarmos de um budismo social estamos falando de uma ideia que já é antiga e que provavelmente é advinda dos tempos em que viveu o próprio Buddha Shakyamuni, onde já se configurava a noção de que sozinho o ser humano não poderia conseguir alcançar a iluminação final, que seria pela ação altruísta e pelo zelo aos outros que esta ideia/noção de lucidez surgiria. Dessa forma, líderes budistas que conseguiram ser reconhecidos e considerados como anunciadores da paz e da equanimidade entre povos e nações, começaram a promover ideias pacifistas altruístas, sendo os elementos mais importantes a dignidade da vida humana, a conservação do meio ambiente e dos animais, e finalmente a compreensão da necessidade de se ter um mundo eco sustentável. Ideias como as que defende o monge vietnamita Thich Nhat Hanh, que lutou contra a predominação de uma guerra injusta no Vietnã, a qual vitimou populações entendidas como minoritárias, que foram obrigadas a camuflarem suas ideias de paz e de altruísmo por verdades em forma de bombas de governos totalitários. Dessa forma, Thich Nhat Hanh despertou o budismo a trabalhar em prol da paz mundial através de atitudes perante o governo, constituindo movimentos pacifistas em defesa da vida, do bem-estar social e de uma mente altruísta.

\footnotetext{
${ }^{1}$ Os cânones são o que hoje representam os textos (Sutras) ensinados de forma oral pelo Buddha Shakyamuni a seus discípulos. Podemos citar pelo menos quatro cânones: cânone páli, cânone sânscrito, cânone chinês e cânone tibetano. O cânone páli é considerado o mais tradicional, pois reúne, para a tradição mais clássica, os ensinamentos do Buddha. Cf. REDYSON, 2014, p.265-269 e VON HINÜBER, 2001, p. 7-8.
}

Horizonte, Belo Horizonte, v. 14, n. 43, p. 827-858, jul./set. 2016 - ISSN 2175-5841 
Assim como Thich Nhat Hanh, o XIV Dalai Lama também vem trabalhando dentro das perspectivas de um budismo engajado e da cultura de paz para os povos. Efetivamente, não é possível designar onde necessariamente teria nascido as ideias/noções de um budismo engajado, além das mensagens encontradas nos ensinamentos do Buddha, pois o engajamento surge em cada lugar e situação com perspectivas diferenciadas, uns em luta contra regimes militares autoritários, outros contra opressão social ou questões humanitárias. Estas ações, que privilegiam uma cultura de paz, estão circundadas com práticas de autotransformação e valorização da vida humana, assim como expressões sentimentais e principalmente atitudes de compaixão e não-violência ${ }^{2}$. Muitos trabalhos já foram realizados tendo em vista estas concepções humanitárias e de engajamento e, naturalmente, o budismo, dentro do mundo asiático, já sofreu inúmeros desrespeitos de seus direitos 3 .

A história da expansão do budismo no Brasil tem um capítulo bastante singular neste sentido de engajamento social, pois através do Lama Padma Samten e dos trabalhos realizados pelo Centro de Estudos Budistas Bodisatva - CEBB, diversas questões sociais se viram afloradas no repertório do caminho traçado por ele, apresentando assim, novas formas de ler e reler a natureza, o ser humano, a violação de direitos básicos e a acolhida de pessoas em situação de risco, caracterizando-se como ações da ideia/noção de um budismo engajado socialmente.

Lama Padma Samten foi o primeiro brasileiro a ser ordenado em uma linhagem tibetana4. Isso de alguma forma demonstra sua importância dentro do contexto da história do budismo no Brasil, pois, como veremos, sua perspectiva vai

\footnotetext{
${ }^{2}$ Sobre o tema de engajamento budista podem ser consultados os trabalhos: QUEEN, 1996; JONES, 2003 e KOTLER, 1996.

${ }^{3}$ Conferir por exemplo os casos que ocorreram no Tibet, Vietnam, Sri Lanka e Camboja em KING, 2009, p. 67-95.

${ }^{4}$ De fato, o Lama Padma Samten foi o primeiro Lama leigo ordenado no Brasil. Aqui se deve entender que existe uma diferenciação entre reconhecimento de um Tulku (em tibetano sprul sku), renascimento de um grande mestre, que é entronizado ainda criança dentro da linhagem como Lama (daí porque para alguns pesquisadores o budismo tibetano é chamado de Lamaísmo), e a ordenação de alguém que decide seguir o caminho dentro do budismo em prol do Dharma. Este último recebe o nome no ocidente de Lama leigo, isto é, alguém que deixa suas atividades profissionais para trabalhar diretamente com o budismo, e neste processo o aluno leigo passa pelos estágios de estudos monásticos, como por exemplo, o retiro de três anos, três meses e três dias. Cf. TUCCI, 1980, p. 57-58 ou SNELLGROVE; RICHARDSON, 1980, p. 160-169.
}

Horizonte, Belo Horizonte, v. 14, n. 43, p. 827-858, jul./set. 2016 - ISSN 2175-5841 
além de instruções orais de ensinamentos do Buddha e perpassa a necessidade de engajamento para que se possa compreender o sentido do budismo. Por estas e outras questões, o nome do Lama Padma Samten está associado tanto à chegada do budismo no Brasil quanto à chegada da linhagem tibetana Nyingma5, pois poderemos entender sua proposta como uma representação de um budismo novo, com concepções inovadoras e ideias que atraem praticantes brasileiros, por estar enraizado na realidade brasileira. Podemos considerar que hoje no Brasil o budismo alcançou um número de praticantes que demonstra que este tipo de prática encontrou solo e abrigo em nosso país.

A perspectiva utilizada por Lama Padma Samten vincula-se com a linguagem que utiliza em seus ensinamentos, pois é uma linguagem acessível e transmitida de forma animadora e descontraída, onde as experiências pessoais e cotidianas são as bases dos ensinamentos e das vivências ${ }^{6}$. A construção de sua proposta contempla uma educação para a vida pautada na mensagem do Buddha e no budismo engajado, estabelecendo o princípio do não sectarismo, fazendo as pessoas refletirem sobre a responsabilidade social através de uma cultura de paz7, que envolve, naturalmente, o diálogo inter-religioso. O CEBB (Centro de Estudos Budistas Bodisatva) hoje é um dos grupos budistas brasileiros mais organizados no Brasil e que vem crescendo com o passar dos anos, efetivando a vocação do Lama Padma Samten como mestre e referendando sua proposta de um budismo engajado socialmente. Estas ações podem ser vistas nos projetos de centros de práticas, como locais de assistência social, e principalmente como exemplos de humanitarismo com os seres humanos, no enfrentamento de problemas

\footnotetext{
${ }^{5}$ rNying ma pa em tibetano significa Os de estilo antigo.

${ }^{6}$ O Lama Padma Samten é autor de seis livros (2001. 2001a, 2004, 2006, 2006a e 2010), além de capítulos de livros (2008a) e artigos (1997, 2005, 2006b, 2007, 2008b, 2009, 2010a, 2010b, 2010c, 2011, 2011a, 2012, 2013, 2015), seus ensinamentos budistas estão amplamente disponíveis em DVDs, CDs de áudio e CDs de MP3. Várias de suas palestras, ensinamentos e retiros também podem ser visualizados em canais do Youtube ou mesmo pelo Facebook. Pouca coisa dentro dos estudos de budismo no Brasil foi escrita sobre a obra do Lama Padma Samten e, por isso, recorremos às fontes primárias produzidas pelos praticantes do CEBB (uma que já é inclusive uma tese de doutorado) e por pesquisas de campo realizadas pelo autor durante cinco anos.

${ }^{7}$ Entendamos por cultura de paz o método para despertar e focar qualidades positivas, naturalmente presentes em cada ser humano, para que seja possível estabelecer melhores relações consigo, com o outro, com a sociedade e com a biosfera.
}

Horizonte, Belo Horizonte, v. 14, n. 43, p. 827-858, jul./set. 2016 - ISSN 2175-5841 
$\operatorname{cotidianos}^{8}$. Os inúmeros papéis desenvolvidos pelo CEBB, criado pelo Lama Padma Samten, e as ações humanitárias que propõem um engajamento com as populações menos favorecidas e em situação de risco, demonstram um budismo mais compatível com a realidade, com o cotidiano, isto é, mais próximo e fixado nas raízes históricas do Buddha Shakyamuni.

Este trabalho desenvolverá, portanto, a recuperação histórica do CEBB e das atividades desempenhadas pelo Lama Padma Samten, configurando seus principais projetos sociais em direção à tese do engajamento social budista como do Instituto Caminho do Meio e sua escola voltada a valores ambientais; o projeto Casa da Sopa e o NASCEM (Núcleo de Ação Social, Comunitária e Educacional Caminho do Meio), que valorizam a natureza humana como identidade neste mundo. Ao mesmo tempo, objetiva-se recontar a história do CEBB e também do surgimento da revista Bodisatva, veículo de interação entre o budismo e a sociedade. Para isso nos utilizamos de uma análise descritiva das principais características do CEBB e de Lama Padma Samten.

\section{CEBB e o Lama Padma Samten ${ }^{9}$}

Alfredo Aveline (Lama Padma Samten) nasceu em 1949, bacharelou-se e fez mestrado em Física, na Universidade Federal do Rio Grande do Sul (UFRGS), onde depois foi professor desse departamento, entre 1969 e 1994, trabalhando quase que especificamente com teoria quântica e teoria da complementariedade, do dinamarquês Niels Bohr. A possibilidade de inúmeras relações entre a teoria quântica e o budismo foi responsável por levar o professor à prática do budismo zen, inicialmente. Em carta a Wilson Paranhos, Aveline explica sua chegada ao budismo zen.

\footnotetext{
${ }^{8}$ Atualmente existem aproximadamente 50 CEBBs no Brasil e cerca de 8 Centros de retiro administrados pelo Lama Padma Samten. Cf. http://www.cebb.org.br/centros-no-brasil/, acesso em 29 de setembro de 2016.

${ }_{9}^{9}$ Uma versão primeira deste tópico foi retirada de outro trabalho nosso em que detalhadamente descrevemos os caminhos do budismo no Brasil (REDYSON, 2016).
} 
Meu primeiro contato com o Zen Budismo em 1972 foi através de Celso Marques. Nosso contato principal era na área de ecologia e proteção ambiental. Meu interesse principal na área espiritual se situava no Hinduísmo e na Hatha Yoga. Durante dez anos o Zen Budismo ficou latente e um pouco distante. $\mathrm{Na}$ época, eu o achava um pouco frio, afastado, sem brilho, um pouco triste, um tanto formal (PARANHOS, 1994, p. 154).

Segundo o relato de Aveline, o Zen e o seu modo austero de prática meditativa ainda estavam distantes de suas intenções, pois a alternativa de abandono dos desejos baseava-se, ainda em sua leitura, numa atitude mais voltada ao eu, pois libertar-se do sofrimento era sempre uma atitude e interesse pessoal. Dessa forma, o conhecimento que tinha das práticas dentro do Hinduísmo o levavam a um melhor entendimento do ser humano. Celso Marques era na época professor de Filosofia e já tinha sido iniciado na tradição japonesa do Zen, na Comunidade Soto Zen de São Paulo, por Mestre Tokuda e Ryotan Shingu, desde 1968. Continua a carta de Aveline a Paranhos:

Passei o ano de 1981 praticamente recolhido em casa (de onde só saía para dar minhas aulas na Universidade e cumprir o essencial), mergulhado emocionalmente no Bhagavad-Gita, na obra de Gandhi e de São Francisco de Assis. Isso levou-me ao ponto de pedir uma licença na Universidade e ir morar no meu sítio, juntamente com outros amigos, fundando uma comunidade rural, o Grupo Comunitário Rodeio Bonito, isso como meio de poder aprofundar mais estas experiências (PARANHOS, 1994, p. 154).

Dessa forma, Aveline nos relata que o vazio e a teoria da vacuidade foram preponderantes para seu interesse dentro da doutrina búdica. Para ele, o Sutra do Coração e o Lankavatara Sutra exprimiam uma espécie de vida e de eterna sabedoria, assim como os ensinamentos do sábio zen Mestre Dogen alcançavam profundamente a realização do homem em sua condição humana mais intensa. Aveline se aproximou também de movimentos que tinham encontrado seu auge na Europa e nos EUA, como as manifestações transcendentais nos novos movimentos religiosos, como Hare Krishna e Brahma Kumaris, o que o levou a um congresso de espiritualidade e ciência em Köln (Colônia), na Alemanha, com a finalidade de apresentar um trabalho sobre o Surangama Sutra e a Teoria Quântica. Ressalta 
ainda Aveline que, quando esteve em contato com este movimento, sempre se apresentava como budista.

Com essa compreensão, busquei aprofundar a Visão Budista, aproximeime mais do professor Celso Marques e passei a praticar zazen em sua casa. Lá conheci Kahner San. Avançando por ai, passamos a fazer sesshins em Rodeio Bonito (município de Taquara, RS), um ou dois por ano, durante 1986, 1987 e 1988. Também o Centro de Estudos Budistas (C.E.B.) passou a existir em uma fase inicial pelos textos todos de estudo que eu havia traduzido e continuava traduzindo. Passávamos a estudar em grupo na casa de Celso. (PARANHOS, 1994, p. 155).

O Centro de Estudos Budistas - CEB foi fundado por Aveline em 1986, em Porto Alegre, no intuito de compartilhar a densidade de textos budistas, principalmente do zen, estudado por Aveline desde a década de 1970. Podemos também caracterizar que os retiros realizados em Rodeio Bonito foram de grande importância para que este grupo pudesse aprofundar o desejo da formação do CEB. O filho de Aveline, Ricardo Aveline, em sua tese nos informa.

O CEBB, em sua primeira fase, recebia pessoas interessadas em praticar meditação budista e que possuíam algum vínculo de amizade com os primeiros integrantes da instituição. Eram realizados encontros diários para meditação, quando o então professor Alfredo Aveline, dirigia as práticas com base em estudos sobre o budismo por ele previamente realizados. A prática consistia principalmente na meditação zen budista. Uma vez por semana a meditação contava com a participação de um mestre zen, Kahner San, que morava em Porto Alegre e era amigo de Alfredo Aveline. (AVELINE, 2011, p. 136).

Gerhard Kahner era um praticante do zen de Porto Alegre que muito auxiliou, tanto Aveline quanto Celso Marques, na compreensão dos ditames da prática do zazen ${ }^{10}$. Foi figura importante na constituição dos primeiros grupos zen budistas no eixo sul-sudeste. Fernandes nos informa sobre o momento em que um mestre zen entrou pela primeira vez na sala de prática, criada por Aveline, e junto o sentimento de vê-lo, no CEB, receber e ter a benção do mestre zen Tokuda:

\footnotetext{
${ }^{10}$ Termo em japonês que significa apenas sentar fora introduzido por Mestre Dogen (1.200-1.253 d.C) e hoje se configura como a principal prática do Zen Budismo.
}

Horizonte, Belo Horizonte, v. 14, n. 43, p. 827-858, jul./set. 2016 - ISSN 2175-5841 
Em 1986, Aveline abriu uma sala de meditação no bairro porto-alegrense Menino Deus. O recém nascido Centro de Estudos Budistas (CEB) foi abençoado por Tokuda e desenvolveu muitas atividades na década de 90. (FERNANDES, 2009, p. 24).

Mestre Tokuda fora trazido ao Brasil sob o incentivo do Prof. Rev. Ricardo Mario Gonçalves, na época praticante do zen, que teria viajado ao Japão em busca de material para sua tese de doutorado e para receber iniciações em tradições budistas japonesas como a Soto Zen e a escola Shingon. Tokuda formou muita gente no período em que esteve no Brasil, fundou mosteiros e criou inúmeras sanghas de práticas budistas. Tokuda foi levado a Porto Alegre por Odete Lara, conhecida atriz, que tinha abandonado a carreira para encontrar-se com o zen budismo pelos EUA e, em seguida no Brasil, para que pudesse auxiliar os praticantes gaúchos que se demonstravam entusiasmados com os estudos elaborados por Kahner San. Sobre este episódio nos conta Aveline na carta a Paranhos:

Tudo novo (acabara de terminar a reforma na sala de zazen da Rua Barão do Centro Largo), o Tangka do Buda Shakyamuni, tudo arrumado e chega monge Tokuda. Entra pela porta principal e faz três prostrações. Foi muito emocionante vê-lo reconhecer o lugar. Logo ele consagrou o local e deulhe o nome de Sanguen Dojô, que significa Local para a prática da verdade mais profunda e sutil. (PARANHOS, 1994, p. 157).

Nesta época as atividades de Aveline se tornaram mais intensas e este grupo de praticantes, que sentiu a necessidade de entrar em diálogo com outros grupos de meditação para que não ficassem isolados. Aveline, dessa forma, procura contato com a Sociedade Soto Zen, no bairro da Liberdade em São Paulo, e algum tipo de relação com o budismo zen coreano, em um grupo organizado por Sidney Ramos Seabra. Fez contato também com a Professora Lia Diskin, da Fundação Palas Athena, e com Lincoln Berkeley, sabendo através deles dos planos da vinda de S. S. Dalai Lama ao Brasil, envolvendo-se prontamente também nessa atividade.

Ainda na Carta para Paranhos, Aveline relata como teve seu primeiro contato com uma tradição tibetana e de como ela se revelou uma forma de prática 
meditativa diferenciada: "Algum tempo depois participei em São Paulo de um retiro dirigido pela Ani-La Rinchen Wangmo, discípula do Venerável Kalu Rinpoche, que me abriu a perspectiva do Budismo Tibetano”. (PARANHOS 1994, p. 155).

Ani (Monja em tibetano) Rinchen Wangmo foi na verdade uma precursora dentro do budismo tibetano no Brasil, pois foi sob sua influência que a linhagem Kagyu chegou ao país. Foi ela que, após alguns anos de estudos com lamas tibetanos na Europa, trouxe em 1988 sua Eminência Jamgon Kongtrul Rinpoche ao Rio de Janeiro, um momento que pode ser considerado como o primeiro contato de brasileiros com alguma tradição budista tibetana no Brasil. Continua Aveline:

Em novembro/dezembro desse ano de 1988, Cinthia (esposa de Aveline na época) e eu assistimos ao retiro oferecido por S. E. Jamgon Kongtrul Rinpoche, no Rio, onde tomamos refúgio pela primeira vez e também recebemos nossos nomes religiosos tibetanos na linhagem Karma Kagyu. (PARANHOS, 1994, p. 155) ${ }^{11}$.

Durante o ano de 1989, Alfredo Aveline tomou refúgio Soto Zen através da vinda do mestre Narazaki. Neste mesmo momento diversas pessoas tomaram refúgio zen. Aveline considera este momento muito singular e importante, pois a vinda deste mestre zen ao Brasil acabou por impulsionar cada vez mais o aumento de praticantes brasileiros, aumentava também o interesse destes em conhecer melhor o budismo. Assim, segundo Lama Padma Samten

A década de 90 foi rica em realizações. Houve a fundação da editora Paramita, e a produção do I Ciclo de Debates sobre o Pensamento Budista, que contou com a presença de um dos intérpretes de Sua Santidade, o Dalai Lama, Alexander Berzin. Os ensinamentos oferecidos por ele foram publicados no livro Coração e Mente. José Ignácio Cabezón, ex-tradutor do Dalai Lama, que também deu ensinamentos no CEB. O contato com ele resultou na publicação do livro [...] Diálogos de Bodhgaia. (AVELINE, 2011, p. 136).

\footnotetext{
${ }^{11}$ Tomar refúgio significa acolher as três joias como salutares para a vida, isto é, o Buddha, o Dharma e a Sangha. Alguns pesquisadores entendem que tomar refúgio significa a diferenciação entre o praticante do budismo (aquele que toma refúgio) e o interessado no budismo (aquele que não toma refúgio).
}

Horizonte, Belo Horizonte, v. 14, n. 43, p. 827-858, jul./set. 2016 - ISSN 2175-5841 
O cenário da prática budista no Brasil começava a mudar, o envolvimento de pessoas nestes eventos demonstrava que existia um público interessado. Assim, podemos perceber que a partir desta declaração de Lama Padma Samten começa a se pensar uma consolidação do budismo tibetano em terras brasileiras, em que se destacam dois momentos específicos. O primeiro foi a vinda de S. E. Jamgon Kongtrul Rinpoche e, o segundo, a vinda de S. S. O Dalai Lama ao Brasil. Relato bastante contundente faz Aveline ao descrever o princípio de todo este processo:

Exatamente um ano depois, no exato dia do primeiro aniversário do Sanguen Dojô, em outubro de 1990, estavam em Porto Alegre e presentes no Dojô Soto Zen o secretário de S. S. O Dalai Lama em New York, Rinchen Dharlo, o secretário de S. S. em Dharamsala e ex-presidente do Parlamento Tibetano no exílio, Lodi Gyari, além de Lia Diskin e Odete Lara. Foi uma causalidade de grande alegria para nós. (PARANHOS, 1994, p. 157).

Em 1990 as práticas continuaram intensas e foi fundada a Bodisatva, uma revista de pensamento budista por iniciativa de Aveline, José Fonseca e Ana Elisa Prates. A edição desta revista trouxe uma nova possibilidade de contato entre os grupos budistas, serviria como veículo de divulgação de palestras, horários de práticas e todo tipo de informação sobre o budismo.

Ao final de 1991 as atividades do CEB já estavam bem consolidadas e as práticas de zazen já eram bem efetivas e comuns em diversos espaços. Em Porto Alegre, já havia salas que ofereciam práticas quase todos os dias da semana com Celso Marques, Urbano Rücker, Petrúcio Chalegre (hoje Monge Genshô). Este último desenvolverá no sul do país grupos ligados também a Soto Zen. No entanto, a perspectiva do budismo tibetano começa a preencher lacunas na forma de pensar de Aveline, pois o que até então conhecera demonstrava uma prática concisa e focada em elementos atuais. Podemos considerar que o momento da chegada do budismo tibetano à capital gaúcha, de forma mais intensa, estava muito próxima. A sintonia de Aveline com os mestres tibetanos começou ainda em 1991, como descreve a Paranhos: 
Em outubro de 1991 estive em Nova Iorque para participar da cerimônia e iniciação de Kalachakra e dos cursos preparatórios e iniciações oferecidos pelos líderes das várias linhagens tibetanas, inclusive o Bon. Foi um evento extraordinário, pela primeira vez na história do Dharma uma reunião semelhante, e numa cidade do Ocidente, em Nova Iorque. Lá pude assistir às aulas de todos os grandes mestres tibetanos que estavam representando as diferentes linhagens: Ven. Lati Rinpoche (Gelugpa), Vem. Trulshik Rinpoche (Nyingmapa) por quem senti imediata simpatia e que concordou em receber-me em treinamento no Nepal, Ven. Tenga Rinpoche (Kagyupa),Ven. Kyabje Sakya Trinzin Rinpoche (Sakyapa), Ven. Lopon Tenzin Namdhak Rinpoche (Bon) e Sua Santidade, O Dalai Lama, reverenciado e assistido por todos os mestres presentes, inclusive monges Zen, que deu aulas admiráveis. (PARANHOS, 1994, p. 159).

Assim nestes termos, Aveline também já era sabedor de que alguns mestres tibetanos começavam a nutrir interesse em vir ao Brasil para expandir o Dharma e seus ensinamentos, assim como tinha acontecido com a monja (Ani) Marta Cavalcanti e sua experiência com a linhagem Kagyu. Em 1992, o CEB auxilia a professora Lia Diskin nos preparativos e recepção de S. S. O Dalai Lama no Brasil, trazendo-o também para a cidade de Porto Alegre, o que contribuiu para solidificar as expectativas do budismo tibetano no Brasil.

Muitos mestres tibetanos instalados nos EUA mostraram interesse em vir ao Brasil para expandir seus ensinamentos, erguerem templos de suas tradições e fazerem discípulos, mas um dos primeiros mestres tibetanos que conseguiu realizar isso foi Chagdud Tulku Rinpoche que, em 1992, foi convidado para dar ensinamentos no país e decidiu, no ano seguinte, mudar-se definitivamente para cá, com o intuito de edificar um templo e formar mestres (NICOLODI, 2008, p. 34). Aqui no Brasil, Chagdud encontrou apoio de Aveline e do CEB, e, de alguma forma, "pegou carona" no público que ficara entusiasmado com a vinda de S. S. O Dalai Lama ao Brasil, que teria gerado no estado do Rio Grande do Sul uma vocação à tradição budista tibetana muito intensa. $\mathrm{O}$ mestre tibetano Chagdud Rinpoche fez sua primeira visita ao Brasil já visualizando a implementação de um centro budista Nyingma. Descreve Lama Padma Samten sobre seu encontro com Chagdud: 
Ainda em 1993, chegou à capital gaúcha o Lama Chagdud Tulku Rinpoche. Assim que cheguei ao avião, onde fui busca-lo, senti um grande impacto na proximidade com ele, o que definiu minha decisão de pedir que me aceitasse como aluno e criasse um centro em Porto Alegre. (FERNANDES, 2009, p. 26).

Chagdud Tulku Rinpoche tornou-se um grande mestre na expansão do budismo, desde que chegou no Brasil, inveteradamente começou uma obra que ficou conhecida entre seus alunos com um ato de pura compaixão. Efetivou as perspectivas da criação de templos, na ordenação de lamas e foi preponderante na formação da linhagem Nyingma no Brasil, como assim descreve Nicolodi:

Em 1992, Chagdud foi convidado para dar ensinamentos no Brasil. Decidiu mudar-se para cá e, auxiliado por seu aluno Padma Samten, adquiriu terras na cidade de Três Coroas, no Rio Grande do Sul. Ao visitar o local, afirmou que era uma terra pura. Este era o ano de 1995. Tendo chegado o momento, e para garantir a propagação do Dharma, Rinpoche ordenou diversos lamas que dariam continuidade ao trabalho iniciado por ele. (NICOLODI, 2008, p. 34).

Podemos considerar dessa forma que, com a chegada de Chagdud Rinpoche $^{12}$ ao Brasil, tem início um segundo momento no CEB, que passará a se chamar Centro de Estudos Budistas Bodisatva - CEBB, pois após a ordenação de dois norte-americanos, em 1995, Lama Tsering Everest e Lama Padma Norbu, Alfredo Aveline, que já havia sido aceito como aluno de Chagdud, é chamado pelo mestre para ser ordenado também, pois com a decisão de Rinpoche em fixar residência na cidade de Três Coroas/RS, a inventiva agora seria a construção de um templo. Nasce assim o Chagdud Gonpa Brasil, que passa a ser membro do Chagdud Gonpa, monastério de onde Chagdud Rinpoche é proveniente.

Em dezembro de 1996, Alfredo Aveline foi ordenado por Chagdud Rinpoche, Lama da linhagem Nyingma tibetana, tornou-se o primeiro Lama leigo ordenado no Brasil e se desvinculou de suas atividades da UFRGS:

\footnotetext{
${ }^{12}$ Detalhes da vida de Chagdud podem ser encontrados em sua biografia: RINPOCHE, 2005.
} 
A segunda fase do CEBB iniciou-se em dezembro de 1996, quando o físico Alfredo Aveline foi ordenado lama budista. A cerimônia ocorreu no Khadro Ling em Três Coroas. A partir da ordenação, Alfredo Aveline recebeu o nome budista Padma Samten e iniciou a organização de uma comunidade budista em um sitio na Estrada do Caminho do Meio em Viamão/RS. Junto com o Lama Padma Samten, um grupo de 28 pessoas se organizou para montar uma comunidade budista em um sitio em Viamão. (AVELINE, 2011, p. 137).

Este grupo de pessoas acabou se tornando praticantes, sendo seus integrantes os primeiros alunos do Lama Padma Samten, que juntos auxiliaram a compra do terreno em Viamão, que seria a sede do Instituto Caminho do Meio, vinculando-o ao CEBB e à prática tibetana. Sobre o nome que recebeu, nos diz o Lama Samten:

O nome que (Chagdud) me deu é Padma Samten, o que significa que pertenço à família Lótus, e que vou me manifestar no mundo conectado ao processo pelo qual Amitabha oferece seus ensinamentos, que é essencialmente a meditação em silencio. Samten, aliás, é meditação. Ou seja, meu nome pode ser entendido como Meditação do Lótus. (SAMTEN, 2010, p. 15).

Rapidamente o CEBB e o Instituto Caminho do Meio ganharam uma grande projeção no sul do país, pois ao mesmo tempo em que se fundavam as bases do CEBB, com o Lama Padma Samten, o Khadro Ling, de Chagdud Rinpoche, também se efetivava no Rio Grande do Sul. Mais rapidamente ainda foi a projeção para fora do sul, espalhando-se pela região sudeste e depois nordeste do Brasil. Alves relata que no princípio o terreno comprado serviria para ser dividido entre os praticantes, de forma que pudessem construir casas para moradia: "Por ora, basta dizer que se trata de um terreno que foi dividido em diversos pequenos lotes, que estão servindo de base para a construção de casas de praticantes dedicados ao lama”. (ALVES, 2006, p. 59-60).

Com a morte de Chagdud Rinpoche, em 2002, os templos do Chagdud Gompa Brasil passaram a ser dirigidos espiritualmente por sua viúva, Chagdud Khadro, uma norte-americana, ordenada lama por Chagdud Rinpoche, em 1997, cujo verdadeiro nome era Jane. Teria sido a primeira aluna e intérprete de 
Chagdud desde que este chegou ao ocidente. A partir do Templo de Três Coroas, o Chagdud Gonpa se espalhou pelo sul e sudeste do Brasil. O Caminho de Lama Padma Samten foi diferente, pois embora estivesse ligado à linhagem Nyingma, Padma Samten articulou o Dharma de forma diferente. Seus ensinamentos baseava-se em aspectos sociais e, de alguma forma, isso o fez não estar ligado diretamente ao Chagdud Gonpa regularmente. Efetivamente não existem diferenças doutrinais entre o trabalho de Lama Padma Samten e o trabalho de Chagdud Khadro, quando se fala da continuidade da obra desenvolvida por Chagdud Rinpoche, apenas as formas de ensinamentos mudam um pouco, as adaptações e os veículos para a prática, principalmente quando falamos da recepção do budismo pelo público brasileiro, pois ambos sustentam a tradição Nyingma.

Lama Samten inicia a constituição do CEBB e a institucionalização de inúmeros trabalhos que envolvem a assistência social e o engajamento, passa a promover retiros em diversos lugares do Brasil com a intenção de organizar grupos de prática e, dessa forma, surgem diversos CEBBs, com a intenção de desenvolver a prática da meditação e do estudo de textos clássicos budistas. Lama Samten prefere utilizar-se de uma linguagem acessível a todos, por exemplo, usa o termo Buda, Darma, Sanga, ao invés das formas clássicas de grafá-las. A partir de 2002, começaram a se organizar encontros anuais para deliberar sobre as ações do CEBB e suas práticas complementares. Eventos sobre o diálogo budista e outras formas de conhecimento propiciaram a construção de um templo no estado de Pernambuco, e possibilitou recursos gráficos, como a composição de livros e revistas, como também a divulgação através de novas mídias, como CDs, DVDs, Mp3, entre outros, conforme mencionados acima. Os trabalhos do Lama Padma Samten estão amplamente divulgados através das mídias e dentro de algumas categorias. Podemos afirmar que ele foi o iniciador da utilização destes recursos no Brasil para difundir a mensagem do budismo tibetano. 


\section{O Engajamento social do budismo no CEBB}

Embora não seja a única vertente do budismo engajado, podemos afirmar que esse tipo de budismo, que se engaja socialmente, é um budismo que transporta uma educação de valores para as causas sociais, de cultura de paz, ambientais e etc. Na perspectiva de Kornfield, uma determinada prática espiritual nos leva a uma ação social (KORNFIELD, 1996, p. 14), e, no budismo, esse autor enxerga as mesmas perspectivas que relacionam o papel social de uma tradição religiosa à atividade que, levando o ser humano a espiritualidade, possa também conduzi-lo a participar da realidade social em que cada indivíduo está inserido. Da mesma forma, já nos colocava King (2009) quando projetava que o budismo, igualmente a outras tradições religiosas, teve que passar pelos mesmos caminhos contemporâneos para se estabelecer no ocidente, e que as guerras e os sistemas político-econômicos foram determinantes nisso. A partir dessa perspectiva, a ecologia e os direitos humanos se tornaram muito importantes na defesa da vida e, por consequência, vitais na subsistência do budismo no ocidente. Tudo isso, aliado à prática de meditação e ao convívio com os mestres budistas, tornou o budismo engajado um fato (KING, 2009, p. 7-8).

Os projetos de Lama Padma Samten envolvem ações sociais que possam promover uma cultura de paz e ao mesmo tempo possam estabelecer condições para o respeito à dignidade da pessoa humana e com o meio ambiente, dessa forma, três seriam as ações que atualmente configuram o CEBB como uma instituição que se interessa em auxiliar, dar formação e, portanto, se enquadrar no que chamamos de budismo engajado. Estes projetos seriam o Instituto Caminho do Meio, o NASCEM e a Casa da Sopa.

Nesta perspectiva, o CEBB e a obra criada pelo Lama Padma Samten entendem o budismo como um reflexo de ação social e da cultura de paz, pois a mensagem do Buddha não teria outra finalidade senão beneficiar os seres nas coisas em que estas pessoas mais precisam, isto é, felicidade, condições de vida, 
dignidade e etc. Muitas destas perspectivas, adotadas pelo Lama Samten, eram procuradas até alguns anos atrás na Índia, por exemplo, onde mesmo num um processo de desigualdade religiosa, entre proselitismo religioso e a declaração de nação laica e de direitos humanos, o budismo se manifestava como uma forma de engajamento (RAI, 1995, p. 112-116). Trazendo esta mesma realidade para o Brasil, estes projetos idealizados pelo Lama Samten são realizados em comunidades próximas do CEBB de Viamão, no Rio Grande do Sul e em outras localidades, como Timbaúba/PE, na região metropolitana do Recife, Alto Paraíso em Goiás e Recôncavo baiano.

O Instituto Caminho do Meio surgiu a partir de um sonho auspicioso ${ }^{13}$ de Lama Padma Samten em poder ofertar o ensinamento para a lucidez e conduzir crianças, jovens e adultos a compreender o mundo melhor e a constituir uma sociedade harmônica com o princípio básico da paz universal. Seguindo os passos indicados na tese de Ricardo Aveline (2011, p. 153-154), filho de Lama Padma Samten, o conjunto de atividades sociais do CEBB terão início no ano de 2004 quando o lama percebe que a comunidade do Jardim Castelo (Castelinho), vizinha a sede do CEBB, necessitava de uma determinada assistência, pois não adiantaria cultivar a doutrina do Buddha enquanto que, ao lado, uma comunidade passava por necessidades básicas. Segundo Fernandes:

Este trabalho com o Castelinho teve início em 2004 quando o CEBB Caminho do Meio começou a oferecer oficinas para as mulheres da comunidade. Nos encontros, elas costuravam e trocavam ideias e sonhos. Um dia, Dionísia falou de sua vontade de distribuir sopa para as crianças. (FERNANDES, 2007, p. 23).

Dionísia Machado é a responsável pela distribuição da sopa e seu trabalho demonstra bem o que o Lama Padma Samten entende por comunitarismo. Tem início assim o NASCEM (Núcleo de Ação Social, Comunitária e Educacional Caminho do Meio), que desenvolve ações sociais na comunidade do Castelinho, na

\footnotetext{
${ }^{13}$ Sonho auspicioso é uma terminologia muito utilizada entre os praticantes do budismo tibetano, que se traduz como uma ação arrojada de difundir o Dharma através de ensinamentos, construção de templos que se associou também a trabalhos sociais veiculando a mensagem budista com a ação social.
}

Horizonte, Belo Horizonte, v. 14, n. 43, p. 827-858, jul./set. 2016 - ISSN 2175-5841 
tentativa de unir e envolver os praticantes do CEBB em trabalhos que possam beneficiar os seres, isto é, que através da prática social se alcançaria o estado de mente na qual o budismo interage.

Um dos objetivos do NASCEM é dar suporte ao trabalho de oferecimento de almoços para as crianças do bairro, que já vem sendo feito por Dionísia Machado, moradora do Jardim Castelo, fundadora da Casa da Sopa e presidente do NASCEM. (FERNANDES, 2007, p. 22).

O NASCEM e o projeto Casa da Sopa se configuram como formas práticas, isto é, servem de instrumentos para fazer com que os praticantes do CEBB entendam que o budismo não pode ficar de braços cruzados mediante a situação de risco social, de pobreza e de miséria em que vivem milhões de brasileiros. Os projetos sociais do Lama Padma Samten efetivam também o caráter de engajamento, que o budismo adota como forma de desenvolver em si a bondade, a compaixão e principalmente o benefício dos seres. Ambos os projetos passaram a estar vinculados ao Instituto Caminho do Meio, que surge como um instituto sem fins lucrativos e está localizado na cidade de Viamão, no estado do Rio Grande do Sul.

O Instituto surgiu da percepção de que somos completamente dependentes do mundo vivo ao nosso redor e também do mundo material. Quando vemos o quanto precisamos dos outros, começa a surgir a noção de interdependência, ou seja, de que somos inseparáveis. (INSTITUTO CAMINHO DO MEIO, 2015).

Nutrido por essa concepção, Lama Padma Samten expande seu trabalho social, pois atividades semelhantes acontecem também na comunidade do Coque no Recife (PE), onde também existe o CEBB que, juntamente com o NEIMFA (Núcleo Educacional Irmãos Menores de Francisco de Assis), vem retirando jovens e adolescentes de situações de risco, promovendo formação cultural, cidadania e bem-estar físico e espiritual. No Recife, o CEBB vem contribuindo e instaurando a comunidade do Coque, que foi amplamente marginalizada por sua situação, pobreza e descaso, e que pode ser considerada como um projeto que se enquadra 
na ação de um budismo engajado, assim como fora levantado por Queen e King (QUEEN; KING, 2003, p. 9; KING, 2009, p.10).

O Instituto Caminho do Meio foi constituído juridicamente no ano de 2008 por iniciativa do Lama Padma Samten, presidente do Centro de Estudos Budistas Bodisatva (CEBB), e seus alunos como suporte às atividades de cultura de paz desenvolvidas desde 2002. Foi qualificado como Organização da Sociedade Civil de Interesse Público (OSCIP) pelo Ministério da Justiça em agosto de 2009 (INSTITUTO CAMINHO DO MEIO, 2015).

Outra atividade que pertence ao Instituto é a Escola Caminho do Meio, que se efetiva enquanto escola nas questões pedagógicas para que crianças possam ter a oportunidade de estudo e de formação, condizentes com sua faixa etária. Situada também em Viamão, a Escola Caminho do Meio foi criada para receber crianças budistas e não budistas, orientando-se pela harmonia e cultura de paz.

Nascido do sonho auspicioso de Lama Padma Samten, a Escola Caminho do Meio foi criada em 2008. Iniciou com 5 vagas e oferece atualmente 27 vagas, destinadas à crianças de 1 a 6 anos, distribuídas em três turmas: a Ênfase 1, para crianças de 1 a 2 anos; a Ênfase 2, para as de 2 a 3 anos; e a Ênfase 3, para as de 4 a 6 anos. A escola é gratuita e está vinculada ao Instituto Caminho do Meio. (CASTRO, 2011, p. 25).

Estes princípios. que norteiam a Escola Caminho do Meio, estão baseados no que Lama Padma Samten chama de pedagogia dos cinco Dhyani Budas ${ }^{14}$, que representam uma característica própria do budismo implementado pelo Lama, interconectando o budismo com a vida cotidiana. A proposta desta pedagogia já se tornou projeto de pesquisa junto ao CNPq.

Estes princípios são desenvolvidos na pedagogia dos 5 Diani Budas e do nascimento positivo, ensinadas pelo Lama Padma Samten e já transformada em linha de pesquisa perante o CNPq (Conselho Nacional de Pesquisa), e também junto ao núcleo de Educação e Espiritualidade da Universidade Federal de Pernambuco. O Lama reflete sobre a sabedoria das cinco cores relacionadas a cada um dos 5 Diani Budas. A cor azul

\footnotetext{
${ }^{14}$ Diz respeito aos cinco Budas Dhyani (A palavra Dhyani vem do sânscrito e significa meditação) e são conhecidos como os jinas (conquistadores ou vitoriosos), que não precisam passar pelo estágio de Bodhisattva para alcançar a iluminação. Os cinco Dhyani Budas são: Vairocana (Branco), Akshobhya (azul), Amitabha (vermelho), Amoghasiddhi (verde) e Ratnasambhava (amarelo). Cf. DALAI LAMA, 2003, p. 09.
}

Horizonte, Belo Horizonte, v. 14, n. 43, p. 827-858, jul./set. 2016 - ISSN 2175-5841 
corresponde ao acolhimento; a cor amarela corresponde a generosidade, ouro, beneficio; a cor vermelha é a sabedoria discriminativa e investigativa; a cor verde é a sabedoria da causalidade. Mas tudo culmina na cor branca, ela é a transformação. Organizando seus bimestres conforme essa sequência dos 5 Diani Budas, a escola Caminho do Meio propicia a cada aluno e cada um que ali trabalha vivencie o dar nascimento positivo a si mesmo e a todos os seres. (CASTRO, 2011, p. 2526).

Podemos perceber que as atividades de Lama Padma Samten, dentro dos aspectos de cultura de paz e de responsabilidade universal, constituem uma implementação da prática budista associada à vida cotidiana e que seus projetos sociais vêm demonstrando que o budismo e seus praticantes não podem se eximir de trabalhar em prol do benéfico dos seres através de ações sociais, pois serão elas que transformaram nossas atitudes.

As ações transformadoras almejadas pelo Instituto estão em prática com a Escola Infantil Caminho do Meio, o apoio ao Nascem e à Casa da Sopa na comunidade do Jardim Castelo (Viamão-RS), a Série Diálogos, cursos e seminários formando facilitadores em cultura de paz, e produção e sistematização de conhecimento sobre o tema (INSTITUTO CAMINHO DO MEIO, 2015).

Este é o caminho da iluminação budista, mas iluminação, aqui, pode ser entendida de diversas formas, não há uma existência prefigurada fora da realidade do mundo: iluminação é um conceito que se aproxima da efetividade de nossas realizações. Para o Lama:

Dentro do budismo, a responsabilidade universal e a cultura de paz surgem como meios hábeis extraordinários para o benefício de todos os seres - a começar por nós mesmos. Para nós budistas, a melhor forma de relacionamento com todos os seres é a prática da bondade, amor e compaixão. Cuidar dos outros é a única forma de garantir o nosso próprio bem-estar, pois todos estão interligados, dependemos uns dos outros. (SAMTEN, 2010, p. 151).

O caminho da iluminação, dentro da perspectiva de Lama Padma Samtem, é o caminho da lucidez, não há budismo se não houver lucidez para com os outros seres vivos, para com o meio ambiente, com os menos favorecidos, com as comunidades que são marginalizadas, apenas por estarem ali em situação de 
pobreza. Enfim, o budismo desenvolvido pelo Lama Samten ganha proporções sociais de engajamento que, dentro da doutrina budista, nos traz a reflexão de si mesmo e de como nossa mente funciona.

A mente é um lenço com muitos nós. Utilizar a sabedoria primordial é desatar os nós. Lama Padma Samten retirará esse exemplo dos ensinamentos do Buddha, onde, inicialmente, podemos ver nossa mente como um lenço cheio de nós e, aos poucos, ao ser entendido e compreendido o caminho os nós vão de desfazendo, principalmente o que podemos chamar de sabedoria de samsara, isto é, uma sabedoria deste momento. Ficar pensando o que fazer com o lenço e não saber desatar os nós não adiantará de nada. Ao desatar os nós, nossa mente começa a se liberar de uma ou outra coisa que nos prende ao eu.

\section{A Revista Bodisatva}

A Revista Bodisatva também é um veículo de expressão desse budismo engajado. A revista começou como uma iniciativa de um grupo de meditadores, em especial Alfredo Aveline (Lama Padma Samten), Ana Elisa Prates e José Fonseca, ainda sob os auspícios do CEB (Centro de Estudos Budistas) em Porto Alegre. O nome da revista já anunciava sua finalidade, pois Bodistava revela um ser que auxilia os outros seres a saírem do sofrimento. O primeiro número de Bodisatva saiu na primavera de 1990 e, em seu editorial, José Fonseca escreve:

Há muito tempo que muitos esperavam o primeiro número de Bodisatva. Ai esta ele, graças ao estímulo e à colaboração de um grupo de pessoas interessadas em conhecer o pensamento budista - na sua maioria praticantes do Zen - e ao apoio fundamental da FEEU - Fundação Educacional e Editorial Universalista. É uma edição modesta. O leitor notará que alguns textos lembram mais um capítulo de livro do que um artigo de revista, e que falam principalmente em Zen ou budismo Tibetano. (FONSECA, 1990).

A história da revista Bodisatva caminha em pé de igualdade com a história do antigo CEB, que tem como principal característica reunir praticantes e 
informações sobre as mais diversas tradições do budismo no Brasil. A exemplo disso, o primeiro número é publicado com alguns artigos sobre o zen e com a palestra de Alexander Berzin, em 1 de novembro de 1989, durante o Ciclo de Estudos sobre o Pensamento Budista, realizado em Porto Alegre na UFRGS, que posteriormente publicado como o livro Coração e Mente.

A Bodisatva foi iniciada em parceria com a Fundação Educacional e Editora Universalista - FEEU e, como informado anteriormente, tinha como principal objetivo a divulgação do budismo no Brasil, das salas de práticas e informar notícias budistas pelo mundo. A revista foi enviada para vários lugares, do Brasil e para fora do país, e serviu como primeiro mecanismo de transmissão de informações sobre o budismo, deixando seus leitores sempre informados sobre os acontecimentos budistas, livros que eram lançados, enfim, foi o primeiro meio de divulgação impresso no Brasil sobre budismo. Foi também um meio de trazer textos de mestres zen budistas, como Taisen Deshimaru, Ryotan Tokuda, de mestres tibetanos como a transcrição da palestra de Jamgon Kongtrul Rinpoche, no Rio de Janeiro, de textos do Dalai Lama, entrevistas com Monge Daiju Bitti, Odete Lara, de traduções de ensinamentos de Seung Sahn, Mestre Dogen entre outros.

A dinâmica da revista também avançou com o passar do tempo. Do primeiro número até o número quatro, a revista Bodisatva tinha uma característica mais simples, com um único modelo de capa em todos os números. A partir do número cinco até o sete sua configuração de capa foi alterada e, no número oito, pela primeira vez utilizou-se uma foto para ilustrá-la (o número oito teve o mestre zen Moriyama Roshi e o número nove teve Chagdud Rinpoche na capa). Até o número 11 a revista utilizava o recurso de desenhos em seu interior e podemos considerar que, a partir de 2005, a revista ganhou uma nova formatação, a capa ganhou cores e em seu interior pôde-se utilizar fotografias em preto e branco. Será neste período que o Lama Padma Samten se envolve com as questões sociais e utiliza a Bodisatva para este fim. Assim, podemos considerar que a Revista Bodisatva, até o número 
quatorze, tinha características mais acadêmicas e em 2007 ela passa por uma transformação considerável, muda de tamanho, ganhando um formato de magazine, como afirma Lama Samten no editorial da revista número dezesseis:

Nesta perspectiva, seguindo os passos do Buda, encontramos a nova versão da revista Bodisatva, que desde o número 15 adotou uma forma diferente. Até então, a revista apresentava um perfil mais acadêmico. Hoje ela tem por objetivo ajudar as pessoas a entender suas próprias vidas e a viver de forma mais positiva e feliz. Neste sentido, a Bodisatva passa a enfatizar o trabalho de registrar e aprofundar o esforço budista de responder aos temas contemporâneos, a partir da visão que o próprio Buda desenvolveu em relação à natureza da realidade. (SAMTEN, 2008c, p. 1).

O que Lama Padma Samten demonstra aqui é que o Buddha, após sua iluminação, se dirige a todos os seres e se utiliza de uma linguagem acessível a todos os que o podem ouvir, dessa forma, a revista Bodisatva, que tinha uma aparência mais acadêmica, assim como revistas universitárias, com artigos filosóficos, por exemplo, agora implementava um formato de magazine, com características próprias, com mais fotografias e seções periódicas, possibilitando assim o acesso a todos, e não somente ao público acadêmico. No número dezessete houve nova mudança, que configurou definitivamente a revista:

A revista Bodisatva está com uma nova diagramação. A mudança vem com o resultado das diretrizes surgidas durante o encontro geral de facilitadores do Darma do CEBB, que ocorreu em maio de 2008. Esperamos que não apenas os praticantes, mas também os amigos dos praticantes, os curiosos com respeito ao budismo encontrem ressonância nos textos, nas fotos, no conteúdo. (SAMTEN, 2008a, p. 3).

O alcance que a revista Bodisatva tem hoje dentro da comunidade budista e não budista é muito grande, é a revista de orientação budista que sobreviveu a todas as crises dos momentos do budismo no Brasil, e ela continua sendo periódica e tendo como principal escopo a espiritualidade budista vinculada à ação social, meio ambiente e vida sustentável. 
Outro aspecto, dentro da produção de material referente ao budismo, pode ser vinculado ao Lama Padma Samten, pois por volta de 1989, o ainda Alfredo Aveline fundou a editora Paramita, que não tinha nenhuma vinculação formal com o antigo CEB, e que contava também com o apoio da FEEU. Em outubro de 1991 foi publicado o primeiro livro da editora Paramita: um livro com as palestras do Prof. Alexander Berzin na UFRGS, Coração-e-Mente. O Caminho do Budismo Tibetano (1991). Na apresentação do livro nos diz Aveline:

O prof. Alexander Berzin esteve entre nós na segunda metade de 1989, proferindo cinco conferências e participando de dois debates públicos com professores das áreas de filosofia e física, em atividades promovidas pela Pró-Reitoria de Extensão da UFRGS, pela Sociedade Brasileira para o Progresso da Ciência, pela Associação Palas-Athena de São Paulo, pelo

Centro de Estudos Budistas, pela Associação Cultural GFU, pela Sociedade Teosófica-Loja Dharma, pelo Centro de Estudos de Yoga-CEY e pela Associação Gaúcha de Proteção ao Ambiente Natural-AGAPAN. (AVELINE, 1991, p. 11).

A Editora Paramita ainda publicou, além do livro de Berzin, dois livros de Chagdud Tulku Rinpoche: Portões da Prática Budista (1995) e Vida e Morte no Budismo Tibetano (2008) ${ }^{15}$, e um livro de S. S. O Dalai Lama, Na Terra da Iluminação (1988). Os auspícios que levaram à criação da editora estavam baseados nos princípios de Aveline em oferecer textos de qualidade para os praticantes. Com o encerramento das atividades da editora Paramita, o CEBB assumiu os trabalhos de impressão e acabamento da revista Bodisatva e dos materiais de divulgação budistas.

A obra de Lama Samten é composta de seis livros e inúmeros ensinamentos em DVDs e CDs. A linguagem utilizada pelo Lama é uma linguagem que atrai adeptos, é carismática, sedutora e se utiliza de exemplos práticos do cotidiano das pessoas. Acreditamos que o sucesso do CEBB e dos grupos que se ligaram ao Lama Samten, se deva a estas ações que o tornaram mais perto da realidade das pessoas. Seus livros são livros budistas com uma linguagem para o homem de hoje. Como

\footnotetext{
${ }^{15}$ Ambos os livros de Chagdud Rinpoche ganharam outra edição pela Editora Makara.
} 
escreve Eduardo Bueno no prefácio de um dos livros do Lama: "Provavelmente, o único lama do mundo que consegue explicar o sentido da vida descrevendo um gol do Grêmio - num Gre-Nal, é claro”. (BUENO, 2001, p. 14).

Os três livros iniciais de Lama Samten interagem com esta linguagem, uma linguagem simples para que se possa compreender determinados aspectos do budismo, dos grandes mestres e dos grandes ensinamentos. Nesta linha estão Meditando a Vida (2001), A Joia dos Desejos (2001a) e Mandala do Lótus (2006). Em Meditando a Vida Lama Samten apresenta o Buddha e o Budismo, seus ensinamentos e como eles podem ser praticados na vida cotidiana de cada um. Fala do papel do professor (Guru) que cada um deve encontrar para melhor compreender e seguir os ensinamentos do Buddha e entra na introspecção da prática da meditação. Este é o livro indicado para ser a leitura inicial dentro das sanghas do CEBB. Já o livro A Joia dos Desejos se apresenta de forma mais condensada, coloca as etapas do caminho da prática como a compreensão de samsara, os elementos cognitivos que geram a dor e os estágios do refúgio no Buddha e sua completeza em uma vida de harmonia. O terceiro livro, Mandala do Lótus, revela o aspecto da mandala como cultura de paz que nos leva inevitavelmente a um budismo engajado na ação. Afirma o Lama Samten neste terceiro livro:

O diagnóstico budista de nossa sociedade como um todo é que vivemos um quadro grave de desarticulação social. A desarticulação não significa o rompimento de nossas estruturas de mundo pelo comportamento negativo das pessoas. É mais simples e mais fácil de consertar: nos faltam sonhos, diálogo, energia fluindo de modo natural. Precisamos de sonhos práticos em comum, do diálogo. Precisamos retornar ao sentido de comunidade, precisamos restabelecer a mandala. (SAMTEN, 2006, p. 139).

Mesmo entendendo que o mundo no qual vivemos nos transporta para uma realidade como se fosse uma bolha, Lama Padma Samten escreve que este não pode ser o motivo de uma vida infeliz, isto é, ver a realidade do mundo é uma coisa, entrar nela é outra. O budismo nos ensinaria que ver a realidade é necessário para 
se perceber o que há fora dela, construir um mundo melhor, e para isso o engajamento, outra vez, se faz necessário dentro desta perspectiva.

Em um pequeno livro intitulado Relações e Conflitos (2006a), Lama Samten apresenta o ensinamento de como nos relacionamos conosco, com os outros e com a humanidade, dessa forma enfrentamos uma série de conflitos que podem ser vencidos através de nós mesmos. Em seguida, o Lama Samten apresenta outro livro, O Lama e o Economista. Diálogos sobre budismo, economia e ecologia, dialogando (2004), com o economista Vitor Caruso Jr., onde nos leva a reflexão do sistema atual e as ações do homem, o que envolve economia e o pensamento ecológico frente ao budismo. Seu mais atual livro é A Roda da Vida como caminho para a lucidez (2010), que é um resumo de alguns dos pontos fundamentais da doutrina budista, uma porta aberta ao prajnaparamita e a suas relações filosóficas em direção à lucidez, tanto de espírito como de mente. O projeto de budismo de Lama Samten espelha-se bem nestas palavras na apresentação deste livro:

Ainda que esse livro possa ser útil aos budistas, aspiro de coração que possa ser entendido em âmbitos mais amplos como contribuição não religiosa e não sectária, de mero bom senso, que venha a ressoar internamente com a sabedoria e a lucidez natural de cada um. (SAMTEN, 2010, p. 6).

A obra de Lama Padma Samten não se resume apenas nos livros, ademais, podemos dizer que grande parte de seus ensinamentos estão vinculados a sua produção audiovisual, pois ele acredita que os CDs e DVDs chegam ao público de forma mais fácil, por trazerem a imagem associada ao som. Com isso, o Lama transmite seus ensinamentos que podem ser reproduzidos nas residências, salas de prática, enfim onde for mais conveniente. Esta característica é bem própria de Lama Samten, este processo faz parte de uma ação de transmissão que, através dos meios de comunicação, podem chegar mais rapidamente aos ouvidos dos praticantes, tanto é que existe um grupo de praticantes é responsável pela transcrição dos ensinamentos do Lama. Muitos de seus textos, também, são 
resultados de transcrições de ensinamentos dados nos retiros e palestras ministradas por ele em todo o Brasil, para poderem ser distribuídos nos CEBBs como material de estudo. Seja interpretando um Sutra, como o Sutra do Diamante ou o próprio texto do Prajna Paramita (Sutra do Coração), seja trabalhando os Doze elos da Originação Dependente (Roda da Vida), ou mesmo contando a História de vida do Buda Shakyamuni, o Lama Samten produz uma rede de comunicação muito penetrante, pois ao mesmo tempo que os ensinamentos fluem na mente do praticante, seu modo irreverente de colocar problemas e soluções permite às pessoas perceberem que o budismo não é algo de outro mundo e que esta realização é possível através de ações práticas e efetivas com os outros, consigo mesmo e com a vida sustentável.

\section{Os caminhos do CEBB no Brasil}

A obra de Lama Padma Samten cresceu muito rapidamente, a recepção de seus livros e de seus ensinamentos voltados à atualidade foram responsáveis por uma grande projeção do CEBB nos meios budistas. Suas atividades como mestre cuidador do diálogo e das questões sociais demonstraram que seu trabalho floresceu, pois em praticamente todos os estados do Brasil existe um CEBB ou Grupo de Estudos Budistas Bodisatva - GEBB. A constituição de sua obra nasce com o interesse de um pequeno grupo que deseja ouvir os ensinamentos do Buddha e do Lama Samten, formando assim um GEBB. Em seguida, o GEBB se transforma em CEBB, quando já tem um local de prática definido, quando existe um responsável (tutor) pela sangha, que automaticamente faz parte, ou começa a fazer, do grupo de facilitadores do Dharma, tornando-se aluno do Lama. Dessa forma, espalhando o espírito de compaixão através da prática budista, o CEBB atinge hoje um número considerável de praticantes que demostram o quanto o budismo de tradição tibetana no Brasil cresceu vertiginosamente.

Os CEBBs estão espalhados nas cinco regiões do Brasil, todos sob direção espiritual do Lama Padma Samten e de tutores responsáveis por cada CEBB que 
conduzem as práticas. Lama Samten sempre visita cada CEBB para atender suas necessidades e promover retiros e meios de arrecadar finanças para os projetos que desenvolve. Tutores auxiliam diretamente o Lama nas atividades de prática, pois na atual conjuntura é impossível uma só pessoa fazer isso, dado a extensão que os CEBBs ganharam pelo Brasil, pois além dos grupos de meditação e dos retiros, o Lama é constantemente chamado para participar de congressos, encontros, programas de TV e rádio como forma de transmitir suas mensagens budistas e de vida sustentável.

A região sul é onde está localizado o maior número de CEBBs e onde o budismo tibetano Nyingma é mais forte. No estado do Rio Grande do Sul, os CEBBs estão presentes em: Viamão (sede do Instituto Caminho do Meio), Porto Alegre, Pelotas, Rio Grande e Cassino. No estado de Santa Catarina em: Florianópolis, Joinville, Balneário Camboriú, Garopaba e um na zona rural de Canelinha. No Paraná, há CEBBs em Curitiba e Londrina.

Na região sudeste o CEBB já se encontra no estado de São Paulo: na capital paulista, em Ilha Bela, Maresias, Jundiaí, São José do Rio Preto e em Campinas, de onde retiramos o seguinte relato:

A sanga de Campinas iniciou seus encontros em julho de 2003, após um curso do Lama Padma Samten, na Unipaz. Desde então, vem se reunindo semanalmente, procurando praticar os preciosos ensinamentos do Budismo Tibetano, passados pelo querido Lama Padma Samten. Esta sanga é especialmente eclética, no que diz respeito à origem de seus membros. Seus integrantes formam um grupo vindo de várias cidades, como Tatuí, Araçoiaba da Serra, Jundiaí, São Paulo, São Bernardo do Campo e Campinas (CEBB CAMPINAS, 2015).

No estado do Rio de Janeiro há CEBBs na capital, em Niterói e Petrópolis. Em Minas Gerais, há um CEBB em Belo Horizonte e um GEBB em Juiz de Fora. No Centro-oeste há dois CEBBs: em Brasília e em Alto Paraiso. Na região nordeste há CEBBs na Bahia, em Salvador e no Recôncavo Baiano; em Maceió, na capital alagoana; e em Natal no Rio Grande do Norte. No estado de Pernambuco, o CEBB 
está presente em Recife e Olinda, e em várias salas de meditação e em Darmata, situado na zona rural de Timbaúba/PE, onde há templo e estrutura para retiros. Há também um CEBB na cidade de João Pessoa, na Paraíba. Finalmente, na região norte, há um CEBB na cidade de Porto Velho, em Rondônia. No templo Darmata (Timbaúba/PE), atualmente, vem se tornando, dentro da região nordeste, um dos locais de prática mais constantes, onde o Lama Padma Samten vem dando seus ensinamentos: "Fundado em 2009, em um retiro de duas semanas sobre Prajnaparamita, conduzido pelo Lama, o CEBB Darmata tem realizado desde então dezenas de retiros e cursos" (CENTRO DE ESTUDOS BUDISTAS BODISATVA, 2015).

Darmata é o símbolo da prosperidade dos CEBBs e do sucesso das empreitadas de Lama Padma Samten, pois a estrutura, que foi criada a partir de 2010, remonta a um templo com capacidade para 120 pessoas, e foram construídas casas em um condomínio de moradores do CEBB, além de alojamentos para visitantes. É em Darmata que Lama Samten dá iniciações e aulas de práticas meditativas.

\section{Conclusão}

Desatar os nós da nossa mente (assim como no exemplo do lenço), esse pode ser o entendimento do budismo praticado e ensinado pelo Lama Padma Samten e o CEBB. Uma forma de budismo onde o engajamento social é a primeira instância, onde a cultura de paz e a responsabilidade universal com o ser humano e para com os seres vivos é a característica mais plural desse ensinamento. Lama Padma Samten demonstra que o budismo no Brasil vem crescendo, que os meios de comunicação podem ser utilizados para transmissão de ensinamentos e que todos os recursos possíveis podem ser maneiras para promover o Dharma do Buddha.

Dentro desta perspectiva, podemos perceber que o budismo difundido pelo Lama Padma Samten se configura, inicialmente, dentro da linhagem Nyingma, mas 
que não permanece somente nela, pois a adaptação da linguagem, as diferenciações dos ritos e das práticas começam a identificá-lo como um tipo de budismo a brasileira, uníssono dentro das mensagens do Buddha. Efetivamente, será entre os membros do CEBB que encontraremos praticantes que entendem o budismo como algo compatível com outras tradições religiosas, e por isso podemos encontrar pessoas que frequentam a sala de meditação, os templos, mas que também frequentam a missa católica, por exemplo. O caminho no qual o CEBB percorre hoje é também o do diálogo inter-religioso, coerente com a essência daquilo que pode o ser humano no mundo atual.

Próximo de celebrar 20 anos de ordenação, o Lama Padma Samten desenvolve um trabalho voltado ao diálogo entre culturas e, principalmente, de conscientizar que os seres humanos habitam este mundo e, portanto, têm a responsabilidade universal de mantê-lo e preservá-lo, tanto a natureza como os seres que nela habitam, com dignidade e respeito.

\section{REFERÊNCIAS}

ALVES, Daniel. Notas sobre a condição do praticante budista. Debates do NER, Porto Alegre, ano 7, n. 9, p. 57-80, jan-jun, 2006.

AVELINE, Alfredo. Apresentação. In BERZIN, Alexander. Coração-e-Mente. O Caminho do Budismo Tibetano. Taquara: Paramita, 1991.

AVELINE, Alfredo. A Visão Budista da questão cognitiva. Revista Bodisatva, Viamão, n. 2, p. 46-59, outono, 1991a.

AVELINE, Alfredo. Racionalidade, Cognição, Convicção e verdade. Revista Bodisatva, Viamão, n. 3, p. 39-48, inverno, 1991 b.

AVELINE, Alfredo. O Caminho Direto. Revista Bodisatva, Viamão, n. 6, p. 25-34, verão, 1993.

AVELINE, Alfredo. Seguindo o Mestre espiritual. Revista Bodisatva, Viamão, n. 7, p. 3538, verão, 1994.

AVELINE, Ricardo Strauch. As Transformações históricas do Budismo e suas implicações ético-sociais. 2011. Tese (Doutorado) - Programa de Pós-Graduação em Ciências Sociais, Universidade do Vale do Rio dos Sinos, São Leopoldo.

Horizonte, Belo Horizonte, v. 14, n. 43, p. 827-858, jul./set. 2016 - ISSN 2175-5841 
BARRoS, Maria Thereza da Costa. O Despertar do Budismo no Ocidente. Perspectivas para o século XXI. Rio de Janeiro: Garamond, 2014.

BERZIN, Alexander. Coração-e-Mente. O Caminho do Budismo Tibetano. Taquara: Paramita, 1991.

BUENO, Eduardo. Prefácio: Do Caos ao Lama. In SAMTEN, Lama Padma. Meditando a Vida. São Paulo: Peirópoilis, 2001.

CASTRO, Nea de. Escola Caminho do Meio. Crescer com a sabedoria dos Budas. Revista Bodisatva, Viamão, n. 23, 2011.

CEBB CAMPINAS. Práticas regulares CEBB Campinas. Disponível em: <http://www.cebb.org.br/campinas-praticas/>. Acesso em: 27 abr. 2013.

CENTRO DE ESTUdOS BUDISTAS BODISATVA. História do CEBB Darmata. Disponível em: <http://www.cebb.org.br/historia-do-cebb-darmata/>. Acesso em: 23 abr. 2015 .

DALAI LAMA. O Livro de Ouro da Felicidade. Rio de Janeiro: Agir, 2003.

DALAI LAMA. Na Terra da Iluminação. Taquara. Paramita. 1988.

FERNANDES, Thareja. O Budismo no Brasil. Revista Bodisatva, Viamão, n. 17, p. 16-31, mar. 2009.

HANH, Thich Nhat. Vietnã. Flor de lótus em mar de fogo. Rio de Janeiro: Jorge Zahar Editor, 1968.

INSTITUTO CAMINHO DO MEIO. Sobre o Instituto Caminho do Meio. Disponível em: <http://institutocaminhodomeio.org.br/sobre-o-instituto-caminho-do-meio/>. Acesso em: 12 abr. 2015.

JONES, Ken H. The New Social Face of Buddhism: a call to action. London: Wisdow, 2003 .

KING, Sallie B. Socially Engaged Buddhism. Honolulu: University of Hawaii Press, 2009.

KORNFIELD, Jack. Spiritual Practice and Social Action. in KOTLER, Arnold (Org.) Engaged Buddhist Reader. Ten Years of Engaged Buddhist Publishing. California: Parallax Press, 1996.

KOTLER, Arnold (Org.) Engaged Buddhist Reader. Ten Years of Engaged Buddhist Publishing. California: Parallax Press, 1996.

NICOLODI, Marcelo. Chagdud Tulku Rinpoche. Biografia. Revista Bodisatva, Viamão, n. 16, p. 30-35, jan., 2008. 
PARANHOS, Wilson. Nuvens Cristalinas em luar de prata. Rio de Janeiro: FEEU, 1994.

QUEEN, Chistopher; KING, Sallie (Org.) Engaged Buddhism: buddhist liberation moviments in Southeast Asia. Albany: State University New York Press, 1996.

RAI, Lal Deosa. Human Rights in the Hindu-Buddhist Tradition. Delhi: Nirala, 1995 .

REDYSON, Deyve. Budismo: Da Índia para o Mundo. O Buddha, o Dharma e a Sangha. Revista de Estudos da Religião, São Paulo, v. 14, n. 1, p. 257-278, 2014.

REDYSON, Deyve. Os Caminhos do Dharma no Brasil. História e Desenvolvimento do Budismo no Brasil. Curitiba: Editora CRV, 2016.

RINPOCHE, Chagdud Tulku. O Senhor da Dança. Porto Alegre: Makara, 2005.

RINPOCHE, Chagdud Tulku. Portões da Prática Budista. Taquara. Paramita. 1995.

RINPOCHE, Chagdud Tulku. Vida e Morte no Budismo Tibetano. Três Coroas. Makara. 2008.

SAMTEN, Lama Padma. Mãe de todos os Budas. Revista Bodisatva, Viamão, n. 10, p. 19-24. 1997.

SAMTEN, Lama Padma. A Joia dos desejos. São Paulo: Peirópolis, 2001.

SAMTEN, Lama Padma. Meditando a Vida. São Paulo: Peirópolis, 2001b.

SAMTEN, Lama Padma. O Lama e o Economista. São Carlos: RiMa, 2004.

SAMTEN, Lama Padma. A Roda da Vida. Revista Bodisatva, Viamão, n. 13, p. 56-6o, 2005 .

SAMTEN, Lama Padma. Mandala do Lótus. São Paulo: Peirópolis, 2006.

SAMTEN, Lama Padma. Relações e Conflitos. Viamão: Mandala do Lótus, 2006a.

SAMTEN, Lama Padma. O Caminho da Felicidade. Revista Bodisatva, Viamão, n. 14, p. 42-54, 2006b.

SAMTEN, Lama Padma. O Caminho da Felicidade. Revista Bodisatva, Viamão, n. 15, p. 5-11, 2007.

SAMTEN, Lama Padma. Ciência, Budismo e Paz. In: PELIZZOLI, Marcelo (Org.) Cultura de Paz: Educação do novo tempo. Recife: Editora Universitária/UFPE, p. 19-33, 2008a. 
SAMTEN, Lama Padma. Relações Positivas equilibram o ambiente. Revista Bodisatva, Viamão, n. 16, p. 7-11, 2008b.

SAMTEN, Lama Padma. Editorial. Revista Bodisatva, Viamão, n. 16, p.1, 2008c

SAMTEN, Lama Padma. A Sabedoria budista nas organizações. Revista Bodisatva, Viamão, n. 17, p. 7-12, 2009.

SAMTEN, Lama Padma. Editorial. Revista Bodisatva, Viamão, n. 17, p. 3, 2009 a.

SAMTEN, Lama Padma. A Roda da Vida como caminho para a lucidez. São Paulo: Peirópolis, 2010.

SAMTEN, Lama Padma. Aliança dos humanos, deuses e semideuses. Revista Bodisatva, Viamão, n. 19, p. 7-11, 2010 .

SAMTEN, Lama Padma. Uma Humanidade, uma sanga, um Buda. Revista Bodisatva, Viamão, n. 20, p. 7-12, 2010 .

SAMTEN, Lama Padma. Budismo e Relacionamentos. Revista Bodisatva, Viamão, n. 21, p. 15-25, 2010c.

SAMTEN, Lama Padma. A Arte e o processo de educação no Budismo. Revista Bodisatva, Viamão, n. 23, p. x-y, 2011a.

SAMTEN, Lama Padma. Meditação nos Três Tempos. Revista Bodisatva, Viamão, n. 24, p. 15-20, 2012.

SAMTEN, Lama Padma. Budismo e vida sustentável. Revista Bodisatva, Viamão, n. 25, p. 14-21, 2012a.

SAMTEN, Lama Padma. Vida e Iluminação do Buda. Revista Bodisatva, Viamão, n. 26, p. 15-26, 2013.

SAMTEN, Lama Padma. Justiça e culpa na visão budista. Revista Bodisatva, Viamão, n. 27, p. 10-21, 2015.

SNELlGROVE, David; RICHARDSON, Hugh. A Cultural History of Tibet. New York: Prajna Press, 1980.

TUCCI, Giuseppe. The Religions of Tibet. Berkeley: University of California Press, 1980.

VON HINÜBER, Oskar. A Handbook of Pāli Literature. New Delhi: Munshiram Manoharlal Publishers, 2001.

Horizonte, Belo Horizonte, v. 14, n. 43, p. 827-858, jul./set. 2016 - ISSN 2175-5841 